Check for updates

Cite this: J. Mater. Chem. C, 2018, 6, 1038

\section{Solution-processable, niobium-doped titanium oxide nanorods for application in low-voltage, large-area electronic devices}

\author{
F. A. Alharthi, ${ }^{\text {ab }}$ F. Cheng, ${ }^{a}$ E. Verrelli, ${ }^{c}$ N. T. Kemp, (D) ${ }^{c}$ A. F. Lee, (D) ${ }^{d}$ M. A. Isaacs, (D) e \\ M. O'Neill ${ }^{C}$ and S. M. Kelly iD *a
}

\begin{abstract}
We report for the first time the one-step synthesis of solution-processable, highly crystalline, niobiumdoped titanium dioxide $\left(\mathrm{Nb}-\mathrm{TiO}_{2}\right)$ nanorods in the anatase phase by the hydrolytic condensation of $\mathrm{Ti}\left(\mathrm{O}^{\mathrm{i}} \mathrm{Pr}\right)_{4}$ and niobium(v) ethoxide using oleic acid as a structure-directing and stabilising agent. These novel surface-stabilised nanorods can be easily dispersed in common solvents at relatively high concentration ( $10 \%)$ and deposited as uniform, thin and transparent films on planar substrates for the fabrication of electronic devices. The small size of the nanoparticles synthesized represents an important advance in achieving high- $k$ dielectric thin films smooth enough to be suitable for OFET applications and the plastic electronics filed in general. Preliminary investigations show that the dielectric constant, $k$, of niobium-doped $(7.1 \mathrm{wt} \%)$ titanium dioxide $\left(\mathrm{Nb}-\mathrm{TiO}_{2}\right)$ nanorods at frequencies in the region of $100 \mathrm{kHz}-1 \mathrm{MHz}$, are more a third greater $(k>8)$ than that $(k=6)$ determined for the corresponding undoped titanium dioxide $\left(\mathrm{TiO}_{2}\right)$ nanorods. The current-voltage $(\mathrm{J}-\mathrm{V}$ ) behaviour of these devices reveal that niobium-doping improves, by reducing, the leakage current of these devices, thereby preventing hard dielectric breakdown of devices incorporating these new nanorods.
\end{abstract}

Received 13th September 2017, Accepted 27th December 2017

DOI: $10.1039 / \mathrm{ctc} 04197 \mathrm{~g}$

rsc.li/materials-c unsuited to electronic film fabrication processes and to plastic electronic applications.

Solution-processable high-dielectric constant, $k$, materials are highly sought after as an inexpensive route to plastic electronic devices, and have the potential to replace silicon dioxide as a gate dielectric to enable further miniaturisation of electronic components. Polymers doped with nanoparticles to create high- $k$ polymer composites represent a potentially attractive approach to create high- $k$ gate dielectrics from solution for plastic electronics. However, major challenges of this approach, still to be resolved, include the realization of stable, homogeneous nanoparticle dispersions as well as the tailoring of stable polymer/ nanoparticle interfaces required to achieve the desirable electrical performance. ${ }^{6-8}$

Titanium dioxide is a very promising material for application in hybrid organic/inorganic photovoltaic device applications due to the high dielectric constants of the anatase $(k=31)$ and rutile $(k=\sim 114)$ phases. ${ }^{9,10}$ Resistive switching has also been demonstrated in titanium dioxide thin films designed for application in next-generation, non-volatile memory devices. ${ }^{11}$ In order to render titanium dioxide nanoparticles soluble - and therefore processable - from organic solution, their surface must first be functionalised with organic ligands/surfactants in order to overcome the strong inter-nanoparticle adhesion forces. ${ }^{12}$ Ligands with long, flexible aliphatic chains are often used to 
stabilise spherical or rod-shaped inorganic nanoparticles and thereby inhibit their aggregation/sintering. ${ }^{13}$ Such hybrid organic/ inorganic nanocomposites do not suffer from phase separation over time, since a uniform monolayer of the organic coating is chemically bound to the surface of the nanoparticles. The ability to synthesise short, surface-stabilised, semiconductor nanorods, soluble in common solvents used to deposit semiconductor materials on plastic electronic substrates using spin coating, drop casting, inkjet printing, Doctor blade and related techniques, etc., with a low degree of dispersity, also facilitates the formation of uniform, thin dielectric layers with the desired dielectric and other electrical, electronic and physical properties.

One-dimensional (1D) nanostructures such as nanorods, nanowires, nanobelts and nanotubes, have attracted much attention for optoelectronic applications and photocatalysis due to their anisotropic features, high aspect ratios and high surface-area-to-volume ratios, which offer a high density of sites available for surface reactions, better load-transfer in composites, and higher (interfacial) charge-carrier transfer rates. ${ }^{14}$ Hydrothermal and solvothermal processing, templating, electrospinning and solution-phase reactions have been developed to prepare such titanium dioxide nanorods. ${ }^{15-17}$ The non-hydrolytic synthesis of titanium dioxide nanorods with high crystallinity and organic surface coatings has attracted considerable recent interest in relation to the fabrication of solution-processed plastic electronic devices. ${ }^{18}$ Weller et al. reported a one-step, low-temperature method to prepare well-crystallized oleic acid-capped, titanium dioxide nanorods in the anatase phase by hydrolysis of titanium tetraisopropoxide $\left[\mathrm{Ti}\left(\mathrm{O}^{\mathrm{i}} \mathrm{Pr}\right)_{4}\right]$, using oleic acid as the surfactant and tertiary amines or quaternary ammonium hydroxides as catalysts. ${ }^{19}$ Concentrated colloidal dispersions in organic solvents can be easily prepared from such oleic acid-capped titanium dioxide nanorods. Oleic acid-capped titanium dioxide nanorods have also been prepared from $\mathrm{Ti}\left(\mathrm{O}^{\mathrm{i}} \mathrm{Pr}\right)_{4}$ at higher reaction temperatures of $260-270{ }^{\circ} \mathrm{C} .{ }^{20}$ Shaffer et al. reported the preparation of solution-processable anatase titanium dioxide nanorods by twostep non-hydrolytic condensation reactions between $\mathrm{TiCl}_{4}$ and $\mathrm{Ti}\left(\mathrm{O}^{\mathrm{i}} \mathrm{Pr}\right)_{4}$ in the presence of oleic acid. ${ }^{18}$ Recently, niobiumdoped titanium dioxide $\left(\mathrm{Nb}^{-\mathrm{TiO}_{2}}\right)$ nanorods $(\mathrm{Nb}=3 \mathrm{wt} \%)$ have been prepared by low-temperature $\left(120^{\circ} \mathrm{C}\right)$ hydrolytic condensation of $\mathrm{NbCl}_{5}$ and $\mathrm{Ti}\left(\mathrm{O}^{\mathrm{i}} \mathrm{Pr}\right)_{4}$ in the presence of oleic acid, but the nanorods were not homogenous. ${ }^{21}$

Nanoscale niobium-doped titanium-dioxide particles $\left(\mathrm{Nb}-\mathrm{TiO}_{2}\right)$ have attracted increasing attention due to their electronic properties and potential applications. ${ }^{22-24} \mathrm{Lu}$ et al. showed that optical transparency and electrical conductivity of the niobiumdoped titanium-dioxide $\left(\mathrm{Nb}-\mathrm{TiO}_{2}\right)$ thin films prepared by reactive, remote-plasma sputtering deposition are comparable to those for tin-doped indium oxide $\left(\mathrm{Sn}-\mathrm{TiO}_{2}\right.$ or ITO), offering significant potential for the low-carbon processing of niobiumdoped titanium-dioxide layers $\left(\mathrm{Nb}^{-\mathrm{TiO}_{2}}\right)$ as a substitute for ITO as standard industry electrodes and hole-injecting layers that require scarce and expensive indium. ${ }^{25}$

Kim et al. have successfully used niobium-doped anatase titanium-dioxide nanoparticles as photoanodes in organic dyesensitized solar cells (DSSCs), ${ }^{26}$ while Duta et al. showed that niobium-doped titanium-dioxide multilayer films (1-10 layers) in the anatase phase are suitable for environmental carbon monoxide sensors. ${ }^{27} \mathrm{Yu}$ et al. reported that niobium-doped titanium-dioxide rod electrodes exhibit enhanced electrical conductivity, high reversible capacity, long cycle life and excellent rates capability, and hence can be employed as an anode material in lithium-ion batteries. ${ }^{28}$ More recently, niobiumand indium-doped titanium-dioxide $\left(\mathrm{Nb}-\mathrm{In}-\mathrm{TiO}_{2}\right)$ ceramics were shown to be high-potential dielectric materials. ${ }^{4,5,29}$ Niobium-doped titanium-dioxide ceramics $\left(\mathrm{Nb}_{x} \mathrm{Ti}_{1-x} \mathrm{O}_{2}\right.$, where $x=1-8$ atom\%) with giant permittivity ( $>104$ ) and a very low dielectric loss $(\sim 0.05)$ were prepared by sintering rutile $\mathrm{TiO}_{2}$ and $\mathrm{Nb}_{2} \mathrm{O}_{5}$ mixed powders under flowing $\mathrm{N}_{2}$ at $1400{ }^{\circ} \mathrm{C}$ for $10 \mathrm{~h}^{4}{ }^{4}$ The electron-pinned defect-dipoles were confirmed as the origin of both their high permittivity and low dielectric loss in the high frequency range for resulting $\mathrm{Nb}_{x} \mathrm{Ti}_{1-x} \mathrm{O}_{2}$ ceramics with $x>4$ atom\%. Mandal et al. also reported the enhancement of the dielectric constant of sintered titanium dioxide films upon doping with niobium. ${ }^{5}$ High-density rutile $\mathrm{Ti}_{1-x} \mathrm{Nb}_{x} \mathrm{O}_{2}$ $(x=0.0,0.02,0.04,0.06$ and 0.1$)$ was prepared from a mixture of $\mathrm{TiO}_{2}$ and $\mathrm{Nb}_{2} \mathrm{O}_{5}$ by sintering at $1400{ }^{\circ} \mathrm{C}$ for $48 \mathrm{~h}$. The heterogeneous microstructure consisting of semiconducting grains and insulating grain boundaries was reported to unlock micro-capacitors with high permittivity $(\sim 104$ at room temperature and $1 \mathrm{kHz}$ ). In addition, intrinsic defect dipoles also contributed towards the high permittivity.

Niobium is an excellent foreign atom for isostructural incorporation into the $\mathrm{TiO}_{2}$ lattice because its ionic radii $r\left(\mathrm{Nb}^{5+}\right)=$ $0.064 \mathrm{~nm}$ is close to that of $\mathrm{Ti}^{4+}\left(r\left(\mathrm{Ti}^{4+}\right)=0.0605 \mathrm{~nm}\right){ }^{30}$ Since $\mathrm{Nb}^{5+}$ has one additional valence electron compared to $\mathrm{Ti}^{4+}$, the charge compensation of $\mathrm{Nb}^{5+}$ in substitution to $\mathrm{Ti}^{4+}$ comes from either by the creation of Ti cation vacancy, or by the stoichiometric reduction of $\mathrm{Ti}^{4+}$ to $\mathrm{Ti}^{3+}$, depending upon the ambient oxygen activity. Under oxidizing conditions, incorporated $\mathrm{Nb}$ is compensated ionically by titanium vacancies as showing in the following chemical equilibria:

$$
\begin{gathered}
2 \mathrm{Nb}_{2} \mathrm{O}_{5} \leftrightarrow 4 \mathrm{Nb}_{\mathrm{Ti}}^{\bullet}+\mathrm{V}_{\mathrm{Ti}}^{\prime \prime \prime \prime}+10 \mathrm{O}_{\mathrm{O}}^{\times} \\
{\left[\mathrm{Nb}_{\mathrm{Ti}}^{\bullet}\right]=4\left[\mathrm{~V}_{\mathrm{Ti}}^{\prime \prime \prime \prime}\right]}
\end{gathered}
$$

Under reducing conditions, $\mathrm{Nb}$ incorporation involves electronic compensation by electrons as showing in the following chemical equilibria: ${ }^{31}$

$$
\begin{gathered}
\mathrm{Nb}_{2} \mathrm{O}_{5} \leftrightarrow 2 \mathrm{Nb}_{\mathrm{Ti}}^{\bullet}+2 \mathrm{e}^{\prime}+4 \mathrm{O}_{\mathrm{O}}^{\times}+1 / 2 \mathrm{O}_{2(\mathrm{~g})} \\
{\left[\mathrm{Nb}_{\mathrm{Ti}}^{\bullet}\right]=\mathrm{n}}
\end{gathered}
$$

Here, we report the ex situ synthesis of solution-processable, highly crystalline niobium-doped titanium dioxide $\left(\mathrm{OA}-\mathrm{Nb}^{-} \mathrm{TiO}_{2}\right)$ nanorods by hydrolytic condensation of $\mathrm{Ti}\left(\mathrm{O}^{\mathrm{i}} \mathrm{Pr}\right)_{4}$ and niobium(v) ethoxide $\left[\mathrm{Nb}(\mathrm{OEt})_{5}, \mathrm{NBEO}\right]$ or niobium isopropoxide $\left[\mathrm{Nb}\left(\mathrm{O}^{\mathrm{i}} \mathrm{Pr}\right)_{5}\right.$, NBIO], using oleic acid as a surfactant and surface stabiliser in combination with tertiary amines or quaternary ammonium hydroxides as reaction catalysts. The electrical properties of these oleic-acid-stabilised, niobium-doped titanium dioxide $\left(\mathrm{OA}-\mathrm{Nb}-\mathrm{TiO}_{2}\right)$ 
nanorods were expected to be superior to those of the corresponding non-doped oleic-acid-stabilised, titanium dioxide $\left(\mathrm{OA}-\mathrm{TiO}_{2}\right)$ nanorods, which exhibit high solubility in common organic solvents used to deposit thin, smooth, and transparent films of the solute on device substrates for low-cost, plastic electronic applications using standard processes, such spin coating, drop casting, inkjet printing, Doctor blade techniques, etc. ${ }^{19}$ but low values for the dielectric constant, $k$, and high leakage currents in standard crossbar test devices.

\section{Experimental}

Synthesis of Oleic acid-stabilized, niobium-doped titanium oxide nanorods $\left(\mathrm{OA}-\mathrm{Nb}-\mathrm{TiO}_{2}\right)$

$$
\begin{gathered}
\mathrm{Ti}(\mathrm{OR})_{4}+x \mathrm{R}^{\prime} \mathrm{CO}_{2} \mathrm{H} \rightarrow \mathrm{Ti}(\mathrm{OR})_{4-x}\left(\mathrm{R}^{\prime} \mathrm{CO}_{2}\right)_{x}+x \mathrm{ROH} \\
\mathrm{Nb}(\mathrm{OR})_{5}+x \mathrm{R}^{\prime} \mathrm{CO}_{2} \mathrm{H} \rightarrow \mathrm{Nb}(\mathrm{OR})_{5-x}\left(\mathrm{R}^{\prime} \mathrm{CO}_{2}\right)_{x}+x \mathrm{ROH} \\
\mathrm{R}=-\mathrm{CH}\left(\mathrm{CH}_{3}\right)_{2},-\mathrm{CH}_{2} \mathrm{CH}_{3}, \mathrm{R}^{\prime}=-\mathrm{C}_{17} \mathrm{H}_{33} \\
(\mathrm{OR})_{3-x}\left(\mathrm{R}^{\prime} \mathrm{CO}_{2}\right)_{x} \mathrm{Ti}(\mathrm{OR})+\left(\mathrm{R}^{\prime} \mathrm{CO}_{2}\right) \mathrm{Ti}(\mathrm{OR})_{4-x}\left(\mathrm{R}^{\prime} \mathrm{CO}_{2}\right)_{x-1} \\
\rightarrow(\mathrm{OR})_{3-x}\left(\mathrm{R}^{\prime} \mathrm{CO}_{2}\right)_{x} \mathrm{Ti}-\mathrm{O}-\mathrm{Ti}(\mathrm{OR})_{4-x}\left(\mathrm{R}^{\prime} \mathrm{CO}_{2}\right)_{x-1}+\mathrm{R}^{\prime} \mathrm{CO}_{2} \mathrm{R}
\end{gathered}
$$

$$
\begin{aligned}
& (\mathrm{OR})_{4-x}\left(\mathrm{R}^{\prime} \mathrm{CO}_{2}\right)_{x} \mathrm{Nb}(\mathrm{OR})+\left(\mathrm{R}^{\prime} \mathrm{CO}_{2}\right) \mathrm{Nb}(\mathrm{OR})_{5-x}\left(\mathrm{R}^{\prime} \mathrm{CO}_{2}\right)_{x-1} \\
& \rightarrow(\mathrm{OR})_{4-x}\left(\mathrm{R}^{\prime} \mathrm{CO}_{2}\right)_{x} \mathrm{Nb}-\mathrm{O}-\mathrm{Nb}(\mathrm{OR})_{5-x}\left(\mathrm{R}^{\prime} \mathrm{CO}_{2}\right)_{x-1}+\mathrm{R}^{\prime} \mathrm{CO}_{2} \mathrm{R}
\end{aligned}
$$

$$
\begin{aligned}
& (\mathrm{OR})_{3-x}\left(\mathrm{R}^{\prime} \mathrm{CO}_{2}\right)_{x} \mathrm{Ti}(\mathrm{OR})+\left(\mathrm{R}^{\prime} \mathrm{CO}_{2}\right) \mathrm{Nb}(\mathrm{OR})_{5-x}\left(\mathrm{R}^{\prime} \mathrm{CO}_{2}\right)_{x-1} \\
& \rightarrow(\mathrm{OR})_{3-x}\left(\mathrm{R}^{\prime} \mathrm{CO}_{2}\right)_{x} \mathrm{Ti}-\mathrm{O}-\mathrm{Nb}(\mathrm{OR})_{5-x}\left(\mathrm{R}^{\prime} \mathrm{CO}_{2}\right)_{x-1}+\mathrm{R}^{\prime} \mathrm{CO}_{2} \mathrm{R}
\end{aligned}
$$

$$
\begin{aligned}
& (\mathrm{OR})_{4-x}\left(\mathrm{R}^{\prime} \mathrm{CO}_{2}\right)_{x} \mathrm{Nb}(\mathrm{OR})+\left(\mathrm{R}^{\prime} \mathrm{CO}_{2}\right) \mathrm{Ti}(\mathrm{OR})_{4-x}\left(\mathrm{R}^{\prime} \mathrm{CO}_{2}\right)_{x-1} \\
& \rightarrow(\mathrm{OR})_{4-x}\left(\mathrm{R}^{\prime} \mathrm{CO}_{2}\right)_{x} \mathrm{Nb}-\mathrm{O}-\mathrm{Ti}(\mathrm{OR})_{4-x}\left(\mathrm{R}^{\prime} \mathrm{CO}_{2}\right)_{x-1}+\mathrm{R}^{\prime} \mathrm{CO}_{2} \mathrm{R}
\end{aligned}
$$

$$
\mathrm{ROH}+\mathrm{R}^{\prime} \mathrm{CO}_{2} \mathrm{H} \rightarrow \mathrm{R}^{\prime} \mathrm{CO}_{2} \mathrm{R}+\mathrm{H}_{2} \mathrm{O}
$$

$$
\operatorname{Ti}(\mathrm{OR})_{4-x}\left(\mathrm{R}^{\prime} \mathrm{CO}_{2}\right)_{x}+y \mathrm{H}_{2} \mathrm{O} \rightarrow \operatorname{Ti}(\mathrm{OR})_{4-x-y}\left(\mathrm{R}^{\prime} \mathrm{CO}_{2}\right)_{x}+y \mathrm{ROH}
$$

$$
\mathrm{Nb}(\mathrm{OR})_{5-x}\left(\mathrm{R}^{\prime} \mathrm{CO}_{2}\right)_{x}+y \mathrm{H}_{2} \mathrm{O} \rightarrow \mathrm{Nb}(\mathrm{OR})_{5-x-y}\left(\mathrm{R}^{\prime} \mathrm{CO}_{2}\right)_{x}+y \mathrm{ROH}
$$

The oleic acid-stabilized, niobium-doped titanium oxide $\left(\mathrm{OA}-\mathrm{Nb}-\mathrm{TiO}_{2}\right)$ nanorods were prepared by co-hydrolysis of titanium(IV) tetraisopropoxide (TTIP) and niobium precursors, niobium isopropoxide (NBIO) and niobium(v) ethoxide (NBEO), using oleic acid as solvent and surfactant at low temperature $\left(100{ }^{\circ} \mathrm{C}\right)$. Trimethylamine $\mathrm{N}$-oxide (TMAO) was added as a catalyst for the polycondensation in order to form a crystalline product in a similar way to titanium alkoxides, which readily react with carboxylic acids in mild conditions to form titanium oxocarboxyalkoxide, see eqn (1). ${ }^{19}$ Niobium oxocarboxyalkoxides are also formed when niobium alkoxides were added in oleic acid at $85{ }^{\circ} \mathrm{C}$, see eqn (2). Ti-O-Ti, Nb-O-Nb and $\mathrm{Ti}-\mathrm{O}-\mathrm{Nb}$ networks formed by non-hydrolytic condensation and/or elimination of an ester, see eqn (3)-(6). ${ }^{19}$ Hydrolysis, see eqn (8) and (9), also occurred after a slow esterification, see eqn (1). The hydrolysis products may continue the non-hydrolytic condensation, see eqn (3)-(6) to further generate Ti-O-Ti, $\mathrm{Nb}-\mathrm{O}-\mathrm{Nb}$ and $\mathrm{Ti}-\mathrm{O}-\mathrm{Nb}$ networks.

Titanium(Iv) tetra-isopropoxide (TTIP, $\geq 97.0 \%$ ), oleic acid (90\%), trimethylamine $N$-oxide (TMAO, 98\%) and niobium(v) ethoxide (NBEO, 99.95\%) were sourced from Sigma-Aldrich. Niobium isopropoxide (NBIO, 99\%) was sourced from Alfa Aesar. Ultrapure water with a specific resistance of $18.2 \mathrm{M} \Omega \mathrm{cm}$ was obtained by reversed osmosis followed by ion-exchange and filtration (UPQ PS system, ELGA, USA). Pure $\mathrm{N}_{2}$ gas cylinder was provided by Energas ltd, UK.

\section{Chemical and physical characterisation}

Fourier transform infrared spectra were recorded on a Nicolet Magna-500 FTIR spectrometer. Transmission electron microscopy (TEM) was collected using a Jeol 2010 TEM running at $200 \mathrm{kV}$. Images were obtained with a Gatan Ultrascan 4000 digital camera. The liquid sample was mixed well in a vial, a $5 \mu \mathrm{L}$ aliquot is placed on a hydrophilic carbon coated copper grid and allowed to air dry. X-ray powder diffraction (XRD) analyses were performed on a PAN analytical Empyrean Series 2 Diffractometer. The concentration of the titanium and barium present in the samples was determined on the Perkin Elmer Optima 5300DV emission ICP instrument. The concentration of carbon, hydrogen and nitrogen present in the samples was analysed by Fisons EA 1108 CHN apparatus. Polarized optical microscopy (POM) was conducted on an Olympus $\mathrm{BH} 2$ polarising microscope, with images taken by polarizers in a perpendicular arrangement. X-ray photoelectron spectroscopy (XPS) was undertaken on a Kratos Axis HSi spectrometer fitted with a charge neutralizer and magnetic focusing lens, employing $\mathrm{Al} \mathrm{K}_{\alpha}$ monochromatic radiation $(1486.7 \mathrm{eV})$. Spectral fitting was performed using CasaXPS version 2.3.14. Binding energies were corrected to the $\mathrm{C} 1 \mathrm{~s}$ peak at $284.6 \mathrm{eV}$ and surface atomic compositions calculated via correction for the appropriate instrument response factors.

\section{Dielectric characterisation}

The electrical properties of oleic-acid-stabilised, niobium-doped $(7.12 \%$ and $5.6 \%)$ titanium dioxide $\left(\mathrm{OA}-\mathrm{Nb}-\mathrm{TiO}_{2}\right)$ nanorods $\mathrm{S} 4$ and S5, respectively, and that of the corresponding non-doped, oleic-acid-stabilised, titanium dioxide $\left(\mathrm{OA}-\mathrm{TiO}_{2}\right)$ nanorods, for comparison purposes, were tested using a crossbar approach. A crossbar device consists of a sandwich of the test material between two metallic electrodes perpendicular to each other, i.e., the bottom and top electrodes. Glass slides cut to size and cleaned using acetone and propan-2-ol were used as substrates. The bottom and top electrodes were made of aluminium, deposited using an E306 Edwards thermal evaporator, and the patterns were created via using a custom made self aligning shadow mask set. The materials were deposited on the bottom electrode patterns via solution processing and spin coating. Solutions of concentrations $10 \mathrm{wt} \%$ in chlorobenzene were used and spincoating was carried out in static mode at $1000 \mathrm{rpm}$ for $30 \mathrm{~s}$ followed by a $10 \mathrm{~min}$ bake at $100{ }^{\circ} \mathrm{C}$. The film thickness was kept in the range $270-320 \mathrm{~nm}$. Due to the small size of the 
nanoparticles used, the surface of these thin films is relatively flat, characterised by a surface roughness of 2-3 nm RMS and good uniformity over large areas with maximum peak-valley height difference of $\sim 25 \mathrm{~nm}$ over a $1 \mu \mathrm{m}^{2}$. Electrical characterisation measurements were carried out in inert environment using a custom built triaxial probe station system equipped with a Solartron 1260 impedance analyser and an Agilent B2912 source measure unit. The dielectric constant of the materials was extracted from the parallel capacitance resulting from analysing the impedance data using a simple R-C (resistance-capacitance) parallel model for our test cross-bar devices.

Experimental details for the synthesis of oleic-acid-stabilised, niobium-doped titanium oxide (OA-Nb-TiO$\left.{ }_{2}\right)$ nanorods $\mathrm{S1}-\mathrm{S6}$

Oleic acid ( $420 \mathrm{~g}$ ) was dried under vacuum for $1 \mathrm{~h}$ at $120{ }^{\circ} \mathrm{C}$ and then allowed to cool to $85{ }^{\circ} \mathrm{C}$. Titanium(Iv) isopropoxide $\left(17.7 \mathrm{~cm}^{3}, 60 \mathrm{mmol}\right)$ was added under nitrogen to form a clear yellow solution. After stirring for 10 minutes, the required amount of niobium precursors was injected quickly to the yellow solution, see Table 1 . Then, a solution of trimethylamine $N$-oxide $(2 \mathrm{M}$, $60 \mathrm{~cm}^{3}$ ) was added rapidly by syringe to the reaction mixture. The reaction temperature was then increased to $100{ }^{\circ} \mathrm{C}$ and the reaction mixture allowed to react for either a further $24 \mathrm{~h}$ or $72 \mathrm{~h}$, see Table 1 . After cooling to room temperature, isopropanol $(1.2 \mathrm{~L})$ was added to the reaction mixture and the resultant precipitate was separated off by centrifugation, washed twice with isopropanol and then dried overnight under vacuum at $30{ }^{\circ} \mathrm{C}$. This solid product was suspended in toluene and then precipitated from this solution by adding acetone before being separated off by centrifugation. This purification step was repeated twice and the resultant solid product dried overnight under vacuum at $30{ }^{\circ} \mathrm{C}$ to give the desired oleic acid-stabilised, niobium-doped titanium dioxide $\left(\mathrm{OA}-\mathrm{Nb}-\mathrm{TiO}_{2}\right)$ nanorods $\mathrm{S} 1-\mathrm{S} 6$, see Table 1.

\section{Results and discussion}

\section{Physical properties}

The effect of the niobium precursors on the oleic-acid-stabilised, niobium-doped titanium oxide $\left(\mathrm{OA}-\mathrm{Nb}-\mathrm{TiO}_{2}\right)$ nanorods $\mathrm{S} 1-\mathrm{S} 6$, see Table 1, can be observed from the products prepared after $72 \mathrm{~h}$ reaction. Analysis by ICP indicates that the molar ratio of $\mathrm{Ti}: \mathrm{Nb}$ in the products $\mathrm{S} 1$ and $\mathrm{S} 2$ prepared using niobium isopropoxide (NBIO) as a reaction precursor was $74.5: 1$ and 77.8:1, respectively, which were much higher than those ( $9: 1$ and 19:1, respectively) for the starting materials (TTiP: NBIO), see Table 1 . However, the molar ratio of $\mathrm{Ti} / \mathrm{Nb}$ in the products $\mathrm{S} 4$ and $\mathrm{S} 6$ prepared using niobium ethoxide (NBEO) as a reaction precursor was 10.2:1 and 18.3:1, respectively, values which are close to those (9:1 and 19:1, respectively) for the starting reagents (TTiP : NBEO), see Table 1. One possible reason is for these differences would be that niobium oxocarboxyethoxide may have a similar non-hydrolytic condensation speed as that of titanium oxocarboxyisopropoxide, which results in products with a similar $\mathrm{Ti}: \mathrm{Nb}$ ratio to that of the starting materials TTiP:NBEO. As for NBIO, the higher Ti:Nb ratio comparing with the starting materials TTiP: NBIO ratio is probably due to the slower non-hydrolytic condensation speed of niobium oxocarboxyisopropoxide compared to that of titanium oxocarboxyisopropoxide.

Table 1 also shows the effect of reaction time on the composition of the oleic acid-stabilised and niobium-doped titanium dioxide $\left(\mathrm{OA}-\mathrm{Nb}-\mathrm{TiO}_{2}\right)$ nanorods $\mathrm{S} 1-\mathrm{S} 6$. It can be seen that the molar ratio of $\mathrm{Ti}: \mathrm{Nb}$ in the product $\mathrm{S} 5$ prepared during a $24 \mathrm{~h}$ reaction is $13.7: 1$, much lower than that $(19.0: 1)$ of the TTiP: NBEO starting materials. At higher reaction times $(72 \mathrm{~h})$, the molar ratio of $\mathrm{Ti}: \mathrm{Nb}$ in $\mathrm{S} 6$ is $18.3: 1$, which is very close to that $(19.0: 1)$ of the TTiP : NBEO starting materials. This difference is possibly due to the fact that some of titanium oxocarboxyisopropoxide may not been have completely converted to oleic acidcaped titanium oxide in the $24 \mathrm{~h}$ reaction, which is supported to some degree by the low product yield for this reaction, i.e., $1.47 \mathrm{~g}$ for S6 compared to $1.20 \mathrm{~g}$ for S5.

The XRD patterns of the oleic-acid-stabilised, niobium-doped titanium dioxide $\left(\mathrm{OA}-\mathrm{Nb}-\mathrm{TiO}_{2}\right)$ nanorods $\mathrm{S} 1$ and $\mathrm{S} 3-\mathrm{S} 6$ and those of the corresponding non-doped oleic-acid-stabilised, titanium dioxide $\left(\mathrm{OA}-\mathrm{TiO}_{2}\right)$ nanorods shown in Fig. 1(a-e and $\mathrm{f}$, respectively) are very similar. ${ }^{19}$ Only peaks attributable to titanium dioxide in the anatase state are observed, with no $\mathrm{Nb}_{2} \mathrm{O}_{5}$ or $\mathrm{NbO}_{2}$, for the oleic-acid-stabilised, niobium-doped titanium dioxide $\left(\mathrm{OA}-\mathrm{Nb}-\mathrm{TiO}_{2}\right)$ nanorods $\mathrm{S} 1$ and $\mathrm{S} 3-\mathrm{S} 6$. These findings suggest that niobium may have been incorporated into the titanium dioxide lattice, ${ }^{32,33}$ or $\mathrm{Nb}_{2} \mathrm{O}_{5}$ or $\mathrm{NbO}_{2}$ may be present in the amorphous form.

The FT-IR spectra of the oleic-acid-stabilised, niobiumdoped titanium dioxide $\left(\mathrm{OA}-\mathrm{Nb}-\mathrm{TiO}_{2}\right)$ nanorods $\mathrm{S} 3-\mathrm{S} 6$, prepared from NBEO, are shown in Fig. 2. The IR absorption peaks observed at 2850, 2920 and $2955 \mathrm{~cm}^{-1}$, attributable to $\mathrm{C}-\mathrm{H}_{3}$, $\mathrm{C}-\mathrm{H}_{2}$ and $\mathrm{C}-\mathrm{H}$ the oleic acid coating with titanium centres of the surface of the nanorods. ${ }^{34,35}$ In addition, the stretch vibrations,

Table 1 Reaction conditions and chemical analysis of the oleic acid-stabilised and niobium-doped titanium dioxide nanorods S1-S6

\begin{tabular}{|c|c|c|c|c|c|c|c|c|c|c|}
\hline Sample & $\mathrm{Nb}$ precursor $^{a}$ & $\mathrm{Ti} / \mathrm{Nb}$ (reaction) & Time (h) & Yield (g) & $\mathrm{Ti}^{b}(\%)$ & $\mathrm{C}^{c}(\%)$ & $\mathrm{H}^{c}(\%)$ & $\mathrm{N}^{c}(\%)$ & $\mathrm{Nb}^{b}(\%)$ & $\mathrm{Ti} / \mathrm{Nb}$ (product) \\
\hline $\mathrm{S} 1$ & NBIO & $9: 1$ & 72 & 1.50 & 41.1 & 19.14 & 3.05 & 0.34 & 1.07 & $74.5: 1$ \\
\hline $\mathrm{S} 2$ & NBIO & $19: 1$ & 72 & 1.47 & 44.1 & 21.24 & 3.30 & 0.49 & 1.10 & $77.8: 1$ \\
\hline $\mathrm{S} 3$ & NBEO & $9: 1$ & 24 & 1.65 & 39.2 & 18.78 & 3.00 & 0.63 & 8.02 & $9.5: 1$ \\
\hline $\mathrm{S} 4$ & NBEO & $9: 1$ & 72 & 1.75 & 37.5 & 19.05 & 2.97 & 0.67 & 7.12 & $10.2: 1$ \\
\hline S5 & NBEO & $19: 1$ & 24 & 1.20 & 39.5 & 18.87 & 2.94 & 0.53 & 5.60 & $13.7: 1$ \\
\hline S6 & NBEO & $19: 1$ & 72 & 1.47 & 39.7 & 21.20 & 3.35 & 0.60 & 4.20 & $18.3: 1$ \\
\hline
\end{tabular}

${ }^{a} \mathrm{NBIO}=$ niobium isopropoxide; NBEO $=$ niobium(v) ethoxide. ${ }^{b}$ ICP. ${ }^{c}$ CHNS. 


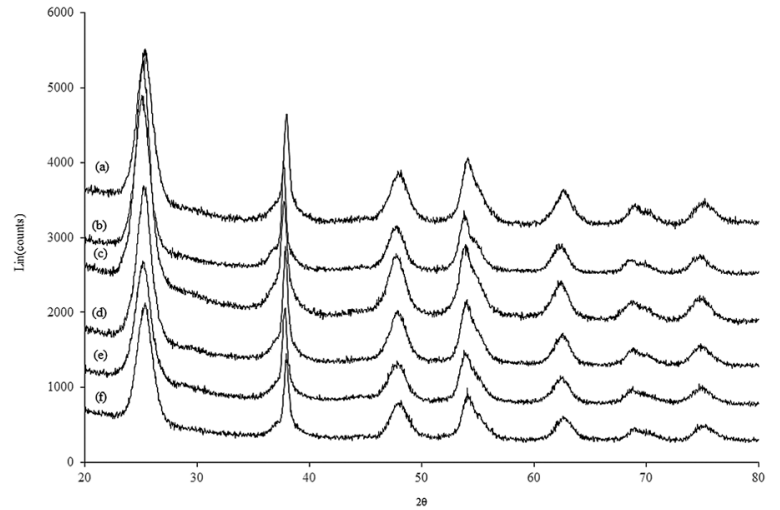

Fig. 1 XRD patterns (a-e) of the oleic-acid-stabilised, niobium-doped titanium dioxide $\left(\mathrm{OA}-\mathrm{Nb}-\mathrm{TiO}_{2}\right)$ nanorods $\mathrm{S} 1$ and $\mathrm{S} 3-\mathrm{S} 6$ and (f) non-doped oleic acid-stabilised titanium dioxide $\left(\mathrm{OA}-\mathrm{TiO}_{2}\right)$ nanorods.

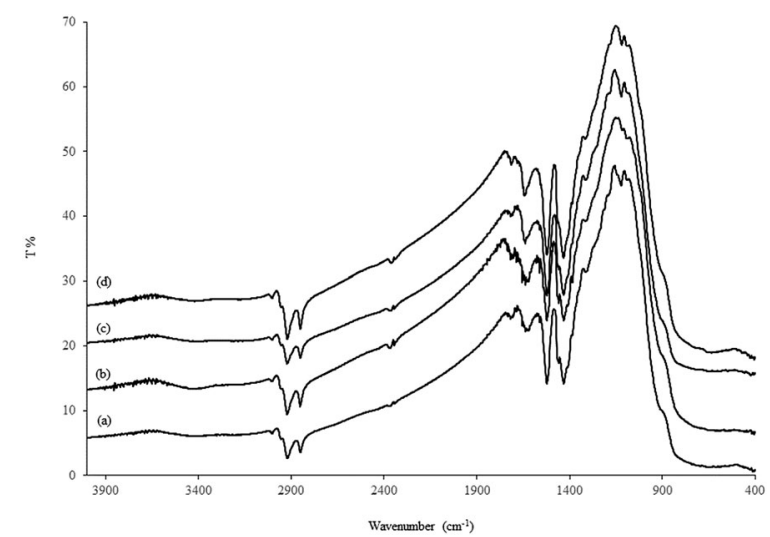

Fig. 2 FT-IR patterns of the oleic acid-stabilised, niobium-doped titanium dioxide nanorods $\left(\mathrm{TiO}_{2}-\mathrm{OA}-\mathrm{Nb}\right.$ ) (a) $\mathrm{S} 3$, (b) $\mathrm{S} 4$, (c) $\mathrm{S} 5$ and (d) $\mathrm{S} 6$.

are indicative of the presence of (organic) oleic acid bound to the surface these (inorganic) nanorods. The two strong peaks at 1525 and $1430 \mathrm{~cm}^{-1}$, a frequency difference around $\Delta \nu_{\mathrm{a}-\mathrm{s}}=95 \mathrm{~cm}^{-1}$, are attributable to asymmetric and symmetric stretching vibrations of the bidentate carboxy $\left(\mathrm{COO}^{-}\right)$group, indicating the interaction of carboxyl groups present in the oleic acid coating with titanium centres of the surface of the nanorods. $^{34,35}$ In addition, the very weak and broad stretch at $3465 \mathrm{~cm}^{-1}$ indicates the presence of trace hydroxyls on the surface of the nanorods. The presence of oleic acid on the surface of the nanorods is also supported by elemental analysis, which indicates the presence of both carbon and hydrogen at relatively high concentrations, i.e., $20 \%$ and $3 \%$, respectively, see Table 1.

Analysis of HRTEM images show that the shape and aspect ratios (5 to 8) of the oleic-acid-stabilised, niobium-doped titanium dioxide $\left(\mathrm{OA}-\mathrm{Nb}-\mathrm{TiO}_{2}\right)$ nanorods S1-S6, see Fig. 3(b-f), are very similar to those of the corresponding non-doped oleic-acidstabilised, titanium dioxide $\left(\mathrm{OA}-\mathrm{TiO}_{2}\right)$ nanorods, see Fig. 3(a), which strongly suggests that the presence of a relatively high concentration of niobium in the former nanorods has very little impact on their shape or size, which again is consistent with
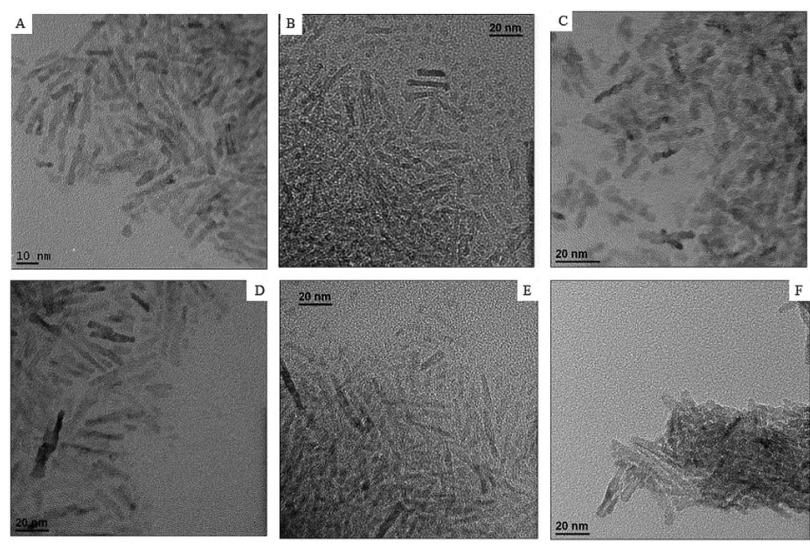

Fig. 3 TEM images of (a) non-doped, oleic acid-stabilised titanium dioxide nanorods $\left(\mathrm{OA}-\mathrm{TiO}_{2}\right)$ and the oleic acid-stabilised, niobium-doped titanium dioxide nanorods $\left(\mathrm{OA}-\mathrm{Nb}-\mathrm{TiO}_{2}\right.$ ) (b) $\mathrm{S} 1$, (c) $\mathrm{S} 3$, (d) $\mathrm{S} 4$, (e) $\mathrm{S} 5$ and (f) $\mathrm{S} 6$.

the incorporation of all of the niobium in the reaction mixture into the titanium dioxide lattice.

The surface composition and chemical environment of the oleic-acid-stabilised, niobium-doped titanium dioxide (OA-Nb$\mathrm{TiO}_{2}$ ) nanorods S4-S6, prepared from NBEO, were investigated using XPS, see Fig. 4 and 5 for high-resolution Nb 3d and Ti 2p $\mathrm{XP}$, respectively. The Ti 2p XP spectra for non-doped oleic-acidstabilised, titanium dioxide $\left(\mathrm{OA}-\mathrm{TiO}_{2}\right)$ nanorods are also shown in Fig. 5 for the purposes of comparison. The surface concentrations and binding energies of $\mathrm{Ti}(\mathrm{III}, \mathrm{IV})$ and $\mathrm{Nb}(\mathrm{IV}, \mathrm{v})$ chemical states derived from XPS peak fitting are summarised in Table 2. The $\mathrm{Nb} 3 \mathrm{~d}$ XP spectra exhibit the characteristic $\mathrm{Nb} 3 \mathrm{~d}$ doublet with $3 \mathrm{~d}_{5 / 2}$ and $3 \mathrm{~d}_{3 / 2}$ spin-orbit components at $207.0 \mathrm{eV}$ and $209.6 \mathrm{eV}$, respectively (Fig. 4). Peak fitting reveals principally $\mathrm{Nb}^{5+}$ at $207.0 \mathrm{eV}^{36}$ and a small contribution from $\mathrm{Nb}^{4+}$ around $205.9 \mathrm{eV}^{37,38}$ The $\mathrm{Nb}^{4+} / \mathrm{Nb}^{5+}$ ratios for $\mathrm{S} 3-\mathrm{S} 6$ are shown in Table 2 and span $0.13-0.08$. We therefore conclude that $\mathrm{Nb}^{5+}$ is the principal dopant within the $\mathrm{TiO}_{2}$ matrix, co-existing with trace $\mathrm{Nb}^{4+}$. Fig. 5 shows that the analogous non-doped oleic-acidstabilised, titanium dioxide $\left(\mathrm{OA}-\mathrm{TiO}_{2}\right)$ nanorods has $2 \mathrm{p}_{3 / 2}$ and $2 \mathrm{p}_{1 / 2} 2 \mathrm{p}$ binding energies of $458.45 \mathrm{eV}$ and $464.10 \mathrm{eV}$, respectively, similar to those observed for all the oleic-acid-stabilised, niobium-doped titanium dioxide (OA- and $2.7 \%$ respectively) is higher than that (2.03\%) determined for the corresponding nondoped oleic-acid-stabilised, titanium dioxide $\left(\mathrm{OA}-\mathrm{TiO}_{2}\right)$ nanorods associated with a small number of oxygen vacancies arising from eqn (11) and (12). ${ }^{4}$ It is well known that the introduction of $\mathrm{Nb}^{5+}$ into $\mathrm{TiO}_{2}$ can increase the $\mathrm{Ti}^{3+}$ content due to charge compensation, as shown in eqn (10) and (12) ${ }^{4,40}$ However, the concentration of $\mathrm{Ti}^{3+}$ determined for $\mathrm{S} 3-\mathrm{S} 6$ is significantly lower than the amount of $\mathrm{Nb}$ introduced $(10$ atom\% for $\mathrm{S} 3$ and S4 and 5 atom\% for S5 and S6). This observation has been previously reported for ceramics doped with high $\mathrm{Nb}$ levels ( $>4$ atom\%). ${ }^{4}$ It was reported that higher $\mathrm{Nb}$ level will provide excessive electrons, which can be captured by oxygen vacancies in eqn (11) to further transform into $\mathrm{O}_{\mathrm{o}}$. Eqn (11) will reduce the concentration of electrons, which in turn will limit the extent of $\mathrm{Ti}^{4+}$ reduction in eqn (12) and hence the $\mathrm{Ti}^{3+}$ concentration. ${ }^{4}$ 


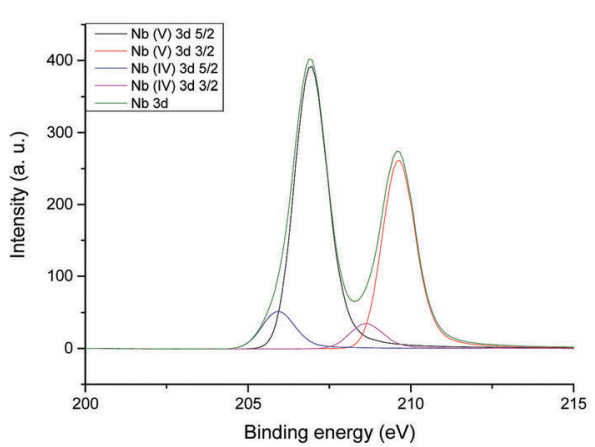

A

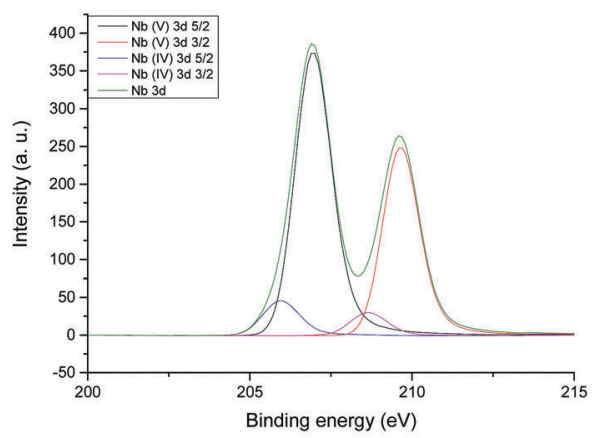

$\mathrm{C}$
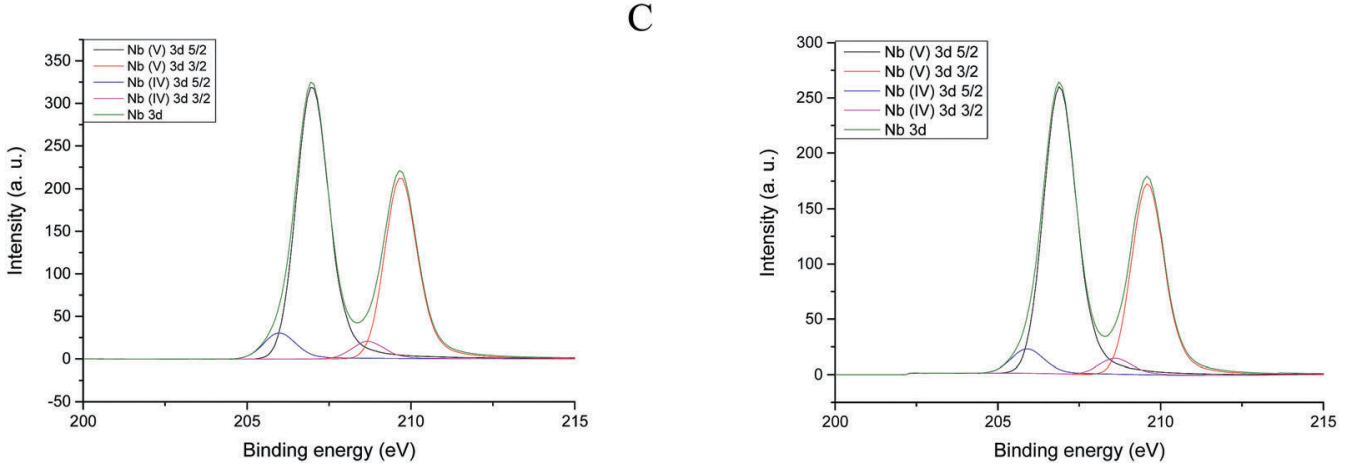

B

$\mathrm{D}$

Fig. $4 \mathrm{Nb} 3 \mathrm{~d}$ XP spectra of the oleic-acid stabilised, niobium-doped titanium dioxide nanorods $\left(\mathrm{TiO}_{2}-\mathrm{OA}-\mathrm{Nb}\right)$, prepared from NBEO, (A) S3, (B) S4, (C) S5 and (D) 56

The $2\left(\mathrm{Nb}^{5+}\right)_{\mathrm{Ti}}^{\bullet} \rightarrow 4\left(\mathrm{Ti}^{3+}\right)_{\mathrm{Ti}}^{\prime} \leftarrow \mathrm{V}_{0}^{\bullet \bullet}$ defect complex, in which electrons and oxygen vacancies are located in the limited lattices, will lead to the formation of electron-pinned defect dipoles. ${ }^{4}$

$$
\begin{gathered}
\mathrm{Nb}_{2} \mathrm{O}_{5} \stackrel{\left(2 \mathrm{TiO}_{2}\right)}{\longrightarrow} 2 \mathrm{Nb}_{\mathrm{Ti}}^{\bullet}+5 \mathrm{O}_{0}+2 \mathrm{e}^{\prime} \\
\mathrm{O}_{0} \rightleftharpoons 2 \mathrm{e}+\mathrm{V}_{0}^{\bullet \bullet}+1 / 2 \mathrm{O}_{2} \uparrow \\
\mathrm{Ti}^{4+}+\mathrm{e} \rightleftharpoons \mathrm{Ti}^{3+}
\end{gathered}
$$

The surface chemical compositions obtained from XPS fitting for the non-doped oleic-acid-stabilised, titanium dioxide $\left(\mathrm{OA}-\mathrm{TiO}_{2}\right)$ nanorods and the corresponding oleic-acid-stabilised, niobium-doped titanium dioxide $\left(\mathrm{OA}-\mathrm{Nb}-\mathrm{TiO}_{2}\right)$ nanorods $\mathrm{S} 4-\mathrm{S} 6$, prepared from NBEO, are shown in Table 3. The atomic ratio of $\mathrm{Ti}$ : Nb was 6.32:1 and 6.23:1 (13.7 and 13.8\% Nb) for S3 and $\mathrm{S} 4$, respectively, somewhat lower than the bulk loadings determined by ICP of $9.5: 1$ and $10.2: 1$ (9.5 and $8.9 \% \mathrm{Nb}$ ). Similarly, the surface atomic ratio of $\mathrm{Ti}: \mathrm{Nb}$ was $8.63: 1$ and $11.85: 1$ (10.4 and $7.8 \% \mathrm{Nb}$ ) for $\mathrm{S} 5$ and $\mathrm{S6}$, respectively, lower than the bulk ICP values of 13.7:1 and 18.3:1 (6.8 and 5.2\% Nb). These findings suggest a slight segregation of niobium on the surface of the titanium dioxide nanorods. Surface segregation and agglomeration of niobium on titanium dioxide fibres and particles has been reported previously ${ }^{30,39}$ driven by the higher oxygen affinity for niobium than titanium. ${ }^{31,38}$ The possible reason for the relative low bulk solubility of niobium in titanium oxide is the low reaction temperature $\left(100{ }^{\circ} \mathrm{C}\right)$. Ruiz et al. reported a solubility limit of $10 \%$ niobium into anatase titania, ${ }^{30}$ but the sample was obtained after heat-treated at $600{ }^{\circ} \mathrm{C}$.

All the oleic-acid-stabilised, niobium-doped titanium dioxide $\left(\mathrm{OA}-\mathrm{Nb}-\mathrm{TiO}_{2}\right)$ nanorods can be readily suspended at relatively high concentration $(10 \mathrm{wt} \%)$ in chlorobenzene, as shown in Fig. 6 for the nanorods S3-S6.

\section{Device performance}

The dielectric constant spectra for the oleic-acid-stabilised, niobium-doped $(7.12 \%$ and $5.6 \%)$ titanium dioxide $\left(\mathrm{OA}-\mathrm{Nb}-\mathrm{TiO}_{2}\right)$ nanorods S4 and S5, respectively, and that of the corresponding non-doped, oleic-acid-stabilised, titanium dioxide $\left(\mathrm{OA}-\mathrm{TiO}_{2}\right)$ nanorods, for comparison purposes, are shown in Fig. 7. All spectra indicate a slight increase of the dielectric constant as the frequency is reduced, which is related to polarisation effects involving the device's interface contribution to the impedance. ${ }^{41}$ The dielectric constant at frequencies in the region of $100 \mathrm{kHz}-1 \mathrm{MHz}$ is around 6 for the non-doped, oleic-acid-stabilised, titanium dioxide $\left(\mathrm{OA}-\mathrm{TiO}_{2}\right)$ nanorod reference material, while it increases to more than 8 for the oleic-acid-stabilised, niobium-doped (7.1 wt\%) titanium dioxide $\left(\mathrm{OA}-\mathrm{Nb}-\mathrm{TiO}_{2}\right)$ nanorods S4. Similarly, currentVoltage leakage current measurements show that an increasing niobium concentration improves the leakage current by reducing it and thereby preventing hard dielectric breakdown, see Fig. 8a. Further analysis of the current-voltage characteristics as shown in Fig. 8b, suggests common current-voltage characteristics of the three nanomaterials tested, i.e., a nearly linear behaviour at low voltages (the slight mismatch with a perfectly linear regime 
A
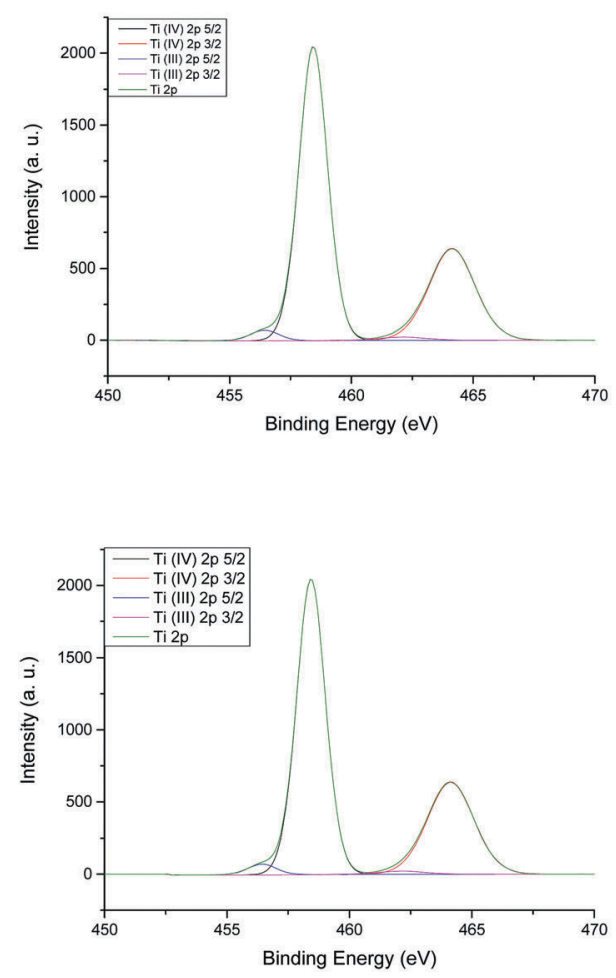

$\mathrm{C}$

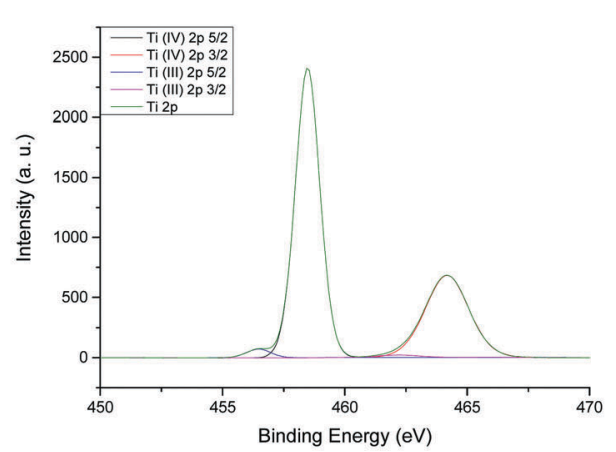

B

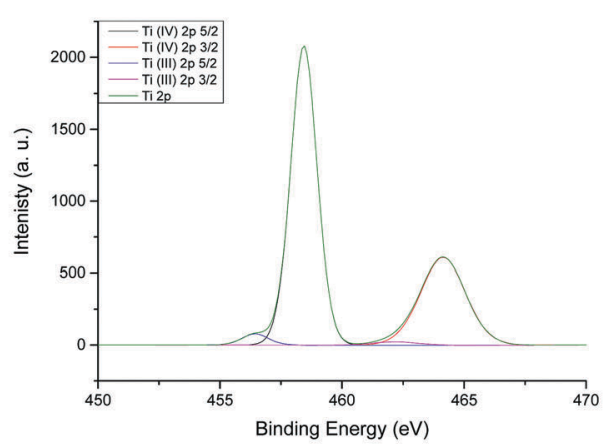

$\mathrm{D}$

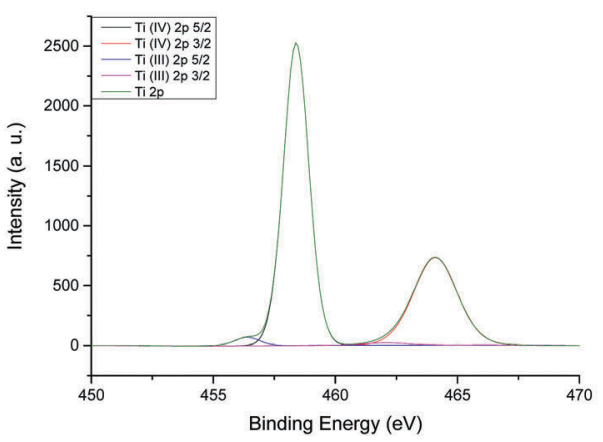

Fig. 5 Ti $2 p$ XP spectra of (A) non-doped oleic-acid-stabilised, titanium dioxide $\left(\mathrm{OA}-\mathrm{TiO}_{2}\right)$ nanorods and the analogous oleic-acid-stabilised, niobiumdoped titanium dioxide $\left(\mathrm{OA}-\mathrm{Nb}-\mathrm{TiO}_{2}\right)$ nanorods, prepared from NBEO (B) S3, (C) S4, (D) S5 and (E) S6.

Table 2 Surface composition and binding energies for Ti(Iv), Ti(III), Nb(V) and $\mathrm{Nb}(\mathrm{IV})$ ions in the non-doped oleic-acid-stabilised, titanium dioxide (OA$\mathrm{TiO} 2)$ nanorods and the corresponding oleic-acid-stabilised, niobium-doped titanium dioxide $\left(\mathrm{OA}-\mathrm{Nb}-\mathrm{TiO}_{2}\right)$ nanorods $\mathrm{S} 4-\mathrm{S} 6$, prepared from $\mathrm{NBEO}$

\begin{tabular}{|c|c|c|c|c|c|c|c|c|}
\hline \multirow[b]{2}{*}{ Sample } & \multicolumn{2}{|l|}{$\underline{\operatorname{Ti}(\mathrm{IV})}$} & \multicolumn{2}{|l|}{$\underline{\operatorname{Ti}(\mathrm{III})}$} & \multicolumn{2}{|l|}{$\mathrm{Nb}(\mathrm{v})$} & \multicolumn{2}{|l|}{$\mathrm{Nb}$ (Iv) } \\
\hline & B.E. (eV) & Loading (atom\%) & B.E. (eV) & Loading (atom\%) & B.E. (eV) & Loading (atom\%) & B.E. $(\mathrm{eV})$ & Loading (atom\%) \\
\hline \multirow{2}{*}{ OA-TiO ${ }_{2}$} & 458.35 & 65.35 & 456.35 & 1.33 & - & - & - & - \\
\hline & 464.05 & 32.66 & 462.05 & 0.66 & - & - & - & - \\
\hline \multirow[t]{2}{*}{ S3 } & 458.43 & 64.25 & 456.44 & 2.43 & 206.88 & 53.02 & 205.88 & 7.02 \\
\hline & 464.14 & 32.11 & 462.14 & 1.21 & 209.58 & 35.29 & 208.58 & 4.67 \\
\hline \multirow[t]{2}{*}{ S4 } & 458.43 & 64.33 & 456.43 & 2.35 & 206.90 & 53.49 & 205.88 & 6.55 \\
\hline & 464.13 & 32.15 & 462.13 & 1.17 & 209.60 & 35.6 & 208.58 & 4.36 \\
\hline \multirow[t]{2}{*}{ S5 } & 458.48 & 64.68 & 462.17 & 3.00 & 206.88 & 54.8 & 205.88 & 5.24 \\
\hline & 464.18 & 36.86 & 456.48 & 1.00 & 209.58 & 36.47 & 208.58 & 3.49 \\
\hline \multirow[t]{2}{*}{ S6 } & 458.40 & 54.80 & 456.40 & 1.80 & 206.88 & 55.38 & 205.88 & 4.66 \\
\hline & 464.10 & 36.47 & 462.10 & 0.90 & 209.58 & 36.86 & 208.58 & 3.10 \\
\hline
\end{tabular}

could be attributed to the very low current level approaching the detection limit of our instrument), followed by a super-linear behaviour at higher voltages with exponent around 5-6. The former could be attributed to a hopping leakage mechanism, ${ }^{42}$ 
Table 3 Surface composition and binding energies of the non-doped oleic-acid-stabilised, titanium dioxide $\left(\mathrm{OA}^{-} \mathrm{TiO}_{2}\right)$ nanorods and the corresponding oleic-acid-stabilised, niobium-doped titanium dioxide $\left(\mathrm{OA}-\mathrm{Nb}-\mathrm{TiO}_{2}\right)$ nanorods $\mathrm{S} 3-\mathrm{S} 6$

\begin{tabular}{|c|c|c|c|c|c|c|c|c|c|c|}
\hline$\frac{\text { Sample }}{\mathrm{OA}^{-\mathrm{TiO}_{2}}}$ & 529.6 & 27.84 & 458.4 & 11.83 & 284.6 & 58.5 & - & - & 398.2 & 1.82 \\
\hline S4 & 529.8 & 30.15 & 458.5 & 10.85 & 284.6 & 56.26 & 207.0 & 1.74 & 401.4 & 1.01 \\
\hline S5 & 529.7 & 32.46 & 458.4 & 12.26 & 284.6 & 52.62 & 207.0 & 1.42 & 339.6 & 1.23 \\
\hline S6 & 529.7 & 29.32 & 458.4 & 11.14 & 284.6 & 57.34 & 206.8 & 0.94 & 402.0 & 1.25 \\
\hline
\end{tabular}

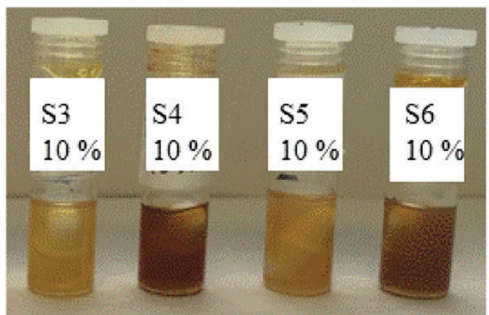

Fig. 6 Photographs of the suspensions of oleic-acid-stabilised, niobiumdoped titanium dioxide $\left(\mathrm{OA}-\mathrm{Nb}-\mathrm{TiO}_{2}\right)$ nanorods $\mathrm{S} 3-\mathrm{S} 6$ at relatively high concentration (10 wt\%) in chlorobenzene.

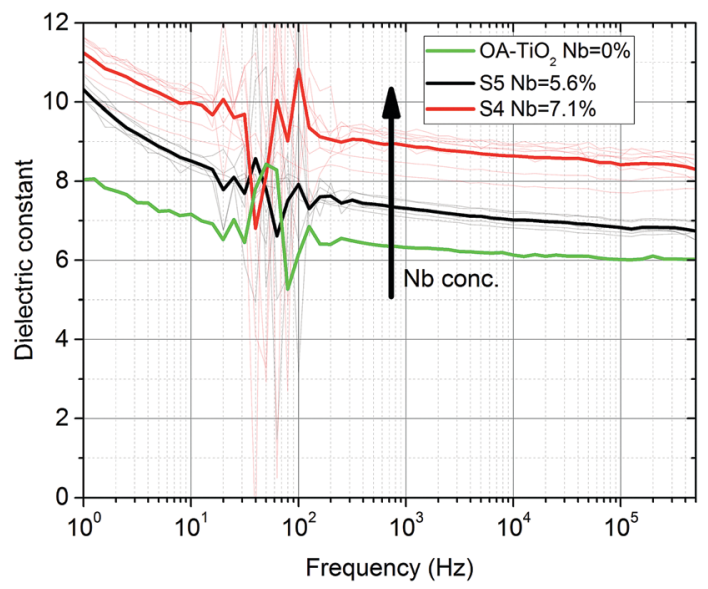

Fig. 7 Dielectric constant spectra for the oleic-acid-stabilised, niobiumdoped titanium dioxide $\left(\mathrm{OA}-\mathrm{Nb}-\mathrm{TiO}_{2}\right)$ nanorods $\mathrm{S} 4$ and $\mathrm{S} 5$ and that of the corresponding non-doped, oleic-acid-stabilised, titanium dioxide $\left(\mathrm{OA}-\mathrm{TiO}_{2}\right)$ nanorods, obtained by analysing the impedance data using an $\mathrm{R}-\mathrm{C}$ parallel model.

while the latter could indicate a trap-assisted mechanism (power behaviours with such high exponents could be attributable to the Poole-Frenkel mechanism ${ }^{42}$ ) although only temperature dependent measurements would allow an in-depth insight in this direction. The major difference between the three trends is the onset voltage of the superlinear regime at $c a .3 \mathrm{~V}$ for the non-doped, oleicacid-stabilised, titanium dioxide $\left(\mathrm{OA}-\mathrm{TiO}_{2}\right)$ nanorod reference material, while it increases to more than $10 \mathrm{~V}$ for the corresponding oleic-acid-stabilised, niobium-doped (7.1 wt\%) titanium dioxide $\left(\mathrm{OA}-\mathrm{Nb}-\mathrm{TiO}_{2}\right)$ nanorods $\mathrm{S} 4$.

Co-doping of titanium dioxide with donor-acceptor dopants has recently received a lot of interest in terms of the creation of materials with colossal permittivity and low, or improved,

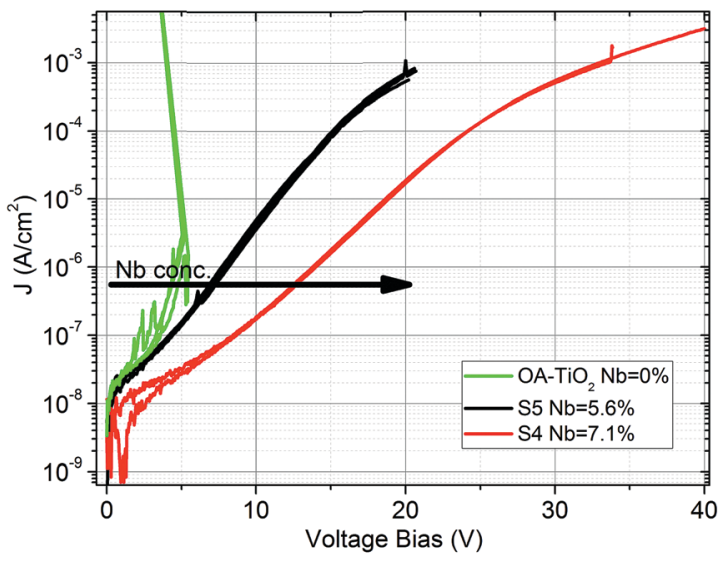

(a)

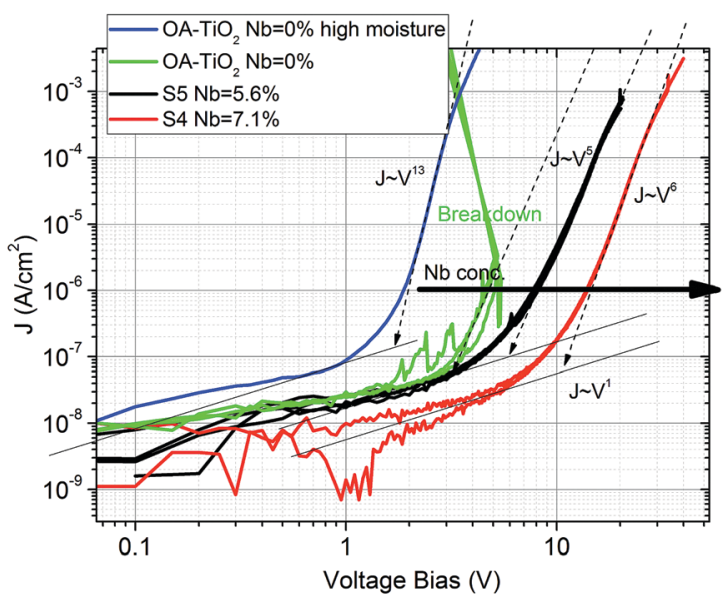

(b)

Fig. 8 Current-voltage leakage current measurements in inert environment for the oleic-acid-stabilised, niobium-doped titanium dioxide $\left(\mathrm{OA}-\mathrm{Nb}-\mathrm{TiO}_{2}\right)$ nanorods S4 and S5 and that of the corresponding non-doped, oleic-acidstabilised, titanium dioxide $\left(\mathrm{OA}-\mathrm{TiO}_{2}\right)$ nanorods, (a) log-linear plot, (b) log-log plot with the high moisture measurement carried out at room temperature and $95 \%$ relative humidity in an oxygen-free environment.

loss. ${ }^{43}$ Niobium is a very common material donor dopant ${ }^{44}$ and niobium doping alone has been reported recently to produce titanium dioxide films with permittivity above $10^{4.44}$ This behaviour could be compatible with the results reported here where niobium doping (7.12\%) of the non-doped, oleic-acidstabilised, titanium dioxide $\left(\mathrm{OA}-\mathrm{TiO}_{2}\right)$ nanorod reference material increases the dielectric constant by a third (from $k=6$ to $k>8$, respectively) for the oleic-acid-stabilised, niobium-doped titanium 
dioxide $\left(\mathrm{OA}-\mathrm{Nb}-\mathrm{TiO}_{2}\right)$ nanorods $\mathrm{S} 4$. While such an increase is remarkable for solution-processable dielectric materials, it is the probably the presence of a low-dielectric-constant, organic capping of oleic acid around the oleic-acid-stabilised, niobium-doped titanium dioxide $\left(\mathrm{OA}-\mathrm{Nb}-\mathrm{TiO}_{2}\right)$ nanorods $\mathrm{S} 4$ and $\mathrm{S} 5$, that actually attenuates the high permittivity enhancement achievable with niobium-doping of titanium dioxide, if the low dielectric constant part was absent. Interestingly, niobium doping has also been used in several works as an effective way to increase the conductivity of titanium dioxide electron transporting layers ${ }^{45}$ or to be used just as alternative transparent conductive oxide. ${ }^{46}$

Higher levels of niobium doping in the oleic-acid-stabilised, titanium dioxide $\left(\mathrm{OA}-\mathrm{Nb}-\mathrm{TiO}_{2}\right)$ nanorods $\mathrm{S} 4$ and $\mathrm{S} 5$ resulted in improved leakage current of the dielectric film, mainly by increasing the effective onset voltage of the super-linear regime. Electron-pinned defect-dipoles arising from the interaction between niobium and oxygen vacancies create reduced dielectric losses $^{44}$ and could support this interpretation of these results. Moreover, leakage current measurement in an inert nitrogen environment, but the presence of high moisture levels shows that the superlinear regime could actually be related to water, likely adsorbed onto titanium dioxide, as shown by the blue curve in Fig. 8b. Thus, it is possible that the observed niobium doping effect on the leakage current could arise from a suppressed water adsorption over the nanorods, due to oxygen vacancy passivation ${ }^{47}$ due to the afore-mentioned interaction between the niobium dopants and oxygen vacancies. ${ }^{44}$

\section{Conclusions}

Novel, low-cost, solution-processable and highly crystalline, niobium-doped titanium dioxide nanorods have been prepared using a one-step hydrolytic condensation reaction. Uniform thin, smooth, and transparent films of these nanorods have been deposited from concentrated solution (10 wt\%) in chlorobenzene by spincoating onto standard crossbar test devices. The dielectric constant $(k>8$ at frequencies in the region of $100 \mathrm{kHz}-1 \mathrm{MHz}$ ) of these oleic-acid-stabilised, niobium-doped $(7.12 \%)$ titanium dioxide $\left(\mathrm{OA}-\mathrm{Nb}-\mathrm{TiO}_{2}\right)$ nanorods is a third higher than that $(k=6)$ of the corresponding non-doped, oleic-acidstabilised, titanium dioxide $\left(\mathrm{OA}-\mathrm{TiO}_{2}\right)$ nanorods used as a reference material. Current-voltage $(J-V)$ leakage current measurements show that a higher niobium concentration improves the leakage current of the test devices by reducing it and preventing hard dielectric breakdown. Electron-pinned defect-dipoles due to electrons and oxygen vacancies located in the limited lattices may be the main reason for the increase of dielectric constant and decrease of dielectric loss in the high frequency range. It is the probably the presence of the low-dielectric-constant organic capping of oleic acid around the niobium-doped titanium dioxide $\left(\mathrm{OA}-\mathrm{Nb}-\mathrm{TiO}_{2}\right)$ nanorods that attenuates the high permittivity enhancement.

\section{Conflicts of interest}

There are no conflicts to declare.

\section{Acknowledgements}

We thank the EPSRC (EP/J001597/1, EP/K021796/1 and EP/K029525/2) and the King Saud University, Deanship of Scientific Research, College of Science Research Centre for financial support. Mrs A. Lowry, Mrs C. Kennedy and Dr R. Knight are thanked for providing TEM, CHN and ICP analyses, respectively.

\section{Notes and references}

1 L. Petti, N. Münzenrieder, C. Vogt, H. Faber, L. Büthe, G. Cantarella, F. Bottacchi, T. D. Anthopoulos and G. Tröster, Appl. Phys. Rev., 2016, 3, 021303.

2 Y. S. Rim, S. H. Bae, H. Chen, N. D. Marco and Y. Yang, $A d v$. Mater., 2016, 28, 4415-4440.

3 K. R. R. Venkata, A. K. Venkata, P. S. Karthik and S. P. Singh, RSC Adv., 2015, 5, 77760-77790.

4 F. Li, B. Shang, P. Ling, L. Wei and Z. Yang, J. Electron. Mater., 2016, 45, 5178-5184.

5 B. P. Mandal, P. Anithakumari, S. Nigam and C. Majumder, New J. Chem., 2016, 40, 9526-9536.

6 M. R. Beaulieu, J. K. Baral, N. R. Hendricks, Y. Y. Tang, A. L. Brisenno and J. J. Watkins, ACS Appl. Mater. Interfaces, 2013, 5, 13096-13103.

7 X. Huang and P. k. Jiang, Adv. Mater., 2015, 27, 546-554.

8 S. Faraji, T. Hashimoto, M. L. Turner and L. A. Majewski, Org. Electron., 2015, 17, 178-183.

9 S. Roberts, Phys. Rev., 1949, 76, 1215-1220.

10 Z. W. Wang, Q. Li, Z. She, F. Chen and L. Li, J. Mater. Chem., 2012, 22, 4097-4105.

11 D. H. Kwon, K. M. Kim, J. H. Jang, J. M. Jeon, M. H. Lee, G. H. Kim, X. S. Li, G. S. Park, B. Lee, S. Han, M. Kim and C. S. Hwang, Nat. Nanotechnol., 2010, 5, 148-153.

12 M. Zorn, S. Meuer, N. T. Muhammad, Y. Khalavka, C. S. Tremel, T. Wolgang and R. Zentel, J. Mater. Chem., 2008, 18, 3050-3058.

13 N. R. Jana, Chem. Commun., 2003, 1950-1951.

14 U. Vukicevic, S. Ziemian (Chyła), A. Bismarck and S. P. Shaffer Milo, J. Mater. Chem., 2008, 18, 3448-3453.

15 S. J. Kwon, H. B. Im, J. E. Nam, J. K. Kang and K. B. Hwang Yi, Appl. Surf. Sci., 2014, 320, 487-493.

16 B. Santara and P. K. Giri, Mater. Chem. Phys., 2013, 137, 928-936.

17 S. Biswas, V. Sundstrom and S. De, Mater. Chem. Phys., 2014, 147, 761-771.

18 R. Menzel, B. F. Cottam, S. Ziemian (Chyla) and S. P. Shaffer Milo, J. Mater. Chem., 2012, 22, 12172-12178.

19 R. D. Cozzoli, A. Kornowski and H. Weller, J. Am. Chem. Soc., 2003, 125, 14539-14548.

20 Z. Zhang, X. Zhong, S. Liu, D. Li and M. Han, Angew. Chem., Int. Ed., 2005, 117, 3532-3536.

21 S. Singh, K. Harjeet, V. N. Singh, K. Jain and T. D. Senguttuvan, Sens. Actuators, B, 2012, 171-172, 899-906.

22 B. N. Joshi, H. Yoon, M. F. A. M. van Hest and S. S. Yoon, J. Am. Ceram. Soc., 2013, 96, 2623-2627.

23 W. Lee, I. Kim, I. Ok, D. Ahn, H. Lee, J.-H. Kim and K. Kim, Thin Solid Films, 2014, 553, 161-165. 
24 H. Usui, S. Yoshioka, K. Wasada, M. Shimizu and H. Sakaguchi, ACS Appl. Mater. Interfaces, 2015, 7, 6567-6573.

25 L. Lu, M. Guo, S. Thornley, X. Han, J. Hu, M. J. Thwaites and G. H. Shao, Sol. Energy Mater. Sol. Cells, 2016, 149, 310-319.

26 S. G. Kim, M. J. Ju, I. T. Choi, W. S. Choi, H.-J. Choi, J.-B. Baek and H. K. Kim, RSC Adv., 2013, 3, 16380-16386.

27 M. Duta, L. Predoana, J. M. Calderon-Moreno, S. Preda, M. Anastasescu, A. Marin, I. Dascalu, P. Chesler, C. Hornoiu, M. Zaharescu, P. Osiceanu and M. Gartner, Mater. Sci. Semicond. Process., 2016, 44, 397-404.

28 X. Yu, L. Xin, Y. Liu, W. Zhao, B. Li, X. Zhouc and H. Shena, RSC Adv., 2016, 6, 27094-27101.

29 Y. Song, X. Wang, Y. Sui, Z. Liu, H. Zhang, B. Zhan and B. Song, Sci. Rep., 2016, 6, 21478.

30 A. M. Ruiz, G. Dezanneau, J. Arbiol, A. Cornet and J. R. Morante, Chem. Mater., 2004, 16, 862-871.

31 L. R. Sheppard, T. Dittrich and M. K. Nowotny, J. Phys. Chem. C, 2012, 116, 20923-20929.

32 B. K. Kaleji, R. S. Mamoory and A. Fujishim, Mater. Chem. Phys., 2012, 132, 210-215.

33 Y. Gao, Thin Solid Films, 1999, 346, 73-81.

34 R. Takahashi, S. Takenaka, S. Sato, T. Sodesawa, K. Ogura and K. Nakanishi, J. Chem. Soc., Faraday Trans., 1998, 94, 3161-3168.

35 M. Nara, H. Torii and M. Tasumi, J. Phys. Chem., 1996, 100, 19812-19817.
36 A. M. Z. Atashbara, H. T. Sun, B. Gong, W. Wlodarski and R. Lam, Thin Solid Films, 1998, 326, 238-244.

37 W. Hu, Y. Liu, R. L. Withers, T. J. Frankcombe, L. Norén, A. Snashall, M. Kitchin, P. Smith, B. Gong, H. Chen, J. Schiemer, F. Brink and J. W. Leung, Nat. Mater., 2013, 12, 821-826.

38 M. Fehse, S. Cavaliere, P. E. Lippens, I. Savych, A. Iadecola, L. Monconduit, D. J. Jones, J. Rozière, F. Fischer, C. Tessier and L. Stievano, J. Phys. Chem. C, 2013, 117, 13827-13835.

39 C. Trapalis, V. Kozhukharov and B. Samuneva, J. Mater. Sci., 1993, 28, 1276-1282.

40 Z. Gai, Z. Cheng, X. Wang, L. Zhao, N. Yin, R. Abah, M. Zhao, F. Hong, Z. Yu and S. Dou, J. Mater. Chem. C, 2014, 2, 6790-6795.

41 E. Barsoukov and J. R. Macdonald, Impedance Spectroscopy: Theory, Experiment, and Applications, 2nd edn, Wiley, 2005.

42 E. Verrelli and D. Tsoukalas, J. Appl. Phys., 2013, 113, 114103.

43 W. Hu, Y. Liu, R. L. Withers, T. J. Frankcombe, L. Norén, A. Snashall, M. Kitchin, P. Smith, B. Gong, H. Chen, J. Schiemer, F. Brink and J. Wong-Leung, Nat. Mater., 2013, 12, 821-826.

44 F. Li, B. Shang, P. Liang, L. Wei and Z. Yang, J. Electron. Mater., 2016, 45, 5178-5184.

45 G. Yin, J. Ma, H. Jiang, J. Li, D. Yang, F. Gao, J. Zeng, Z. Liu and S. F. Liu, ACS Appl. Mater. Interfaces, 2017, 9, 10752-10758.

46 S. Nikodemski, A. A. Dameron, J. D. Perkins, R. P. O’Hayre, D. S. Ginley and J. J. Berry, Sci. Rep., 2016, 6, 32830.

47 Y. Zhao, K. Kita, K. Kyuno and A. Toriumi, Jpn. J. Appl. Phys., Part 1, 2007, 46, 4189-4192. 